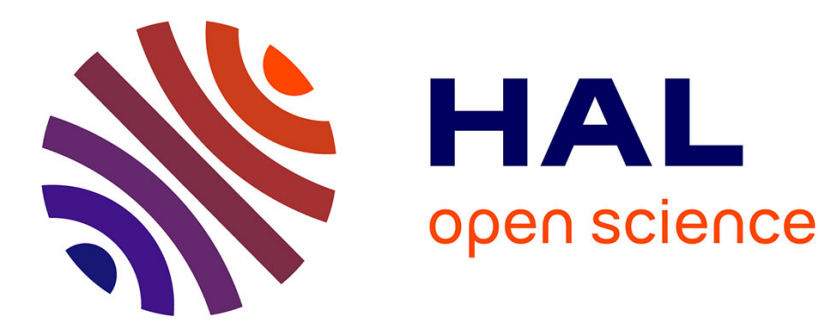

\title{
Sensitivity of the Atlantic Meridional Overturning Circulation to the melting from northern glaciers in climate change experiments
}

D. Swingedouw, P. Braconnot, O. Marti

\section{- To cite this version:}

D. Swingedouw, P. Braconnot, O. Marti. Sensitivity of the Atlantic Meridional Overturning Circulation to the melting from northern glaciers in climate change experiments. Geophysical Research Letters, 2006, 33 (7), pp.L07711. 10.1029/2006GL025765 . hal-03023546

\author{
HAL Id: hal-03023546 \\ https://hal.science/hal-03023546
}

Submitted on 2 Dec 2020

HAL is a multi-disciplinary open access archive for the deposit and dissemination of scientific research documents, whether they are published or not. The documents may come from teaching and research institutions in France or abroad, or from public or private research centers.
L'archive ouverte pluridisciplinaire HAL, est destinée au dépôt et à la diffusion de documents scientifiques de niveau recherche, publiés ou non, émanant des établissements d'enseignement et de recherche français ou étrangers, des laboratoires publics ou privés. 


\title{
Sensitivity of the Atlantic Meridional Overturning Circulation to the melting from northern glaciers in climate change experiments
}

\author{
D. Swingedouw, ${ }^{1}$ P. Braconnot, ${ }^{1}$ and O. Marti ${ }^{1}$ \\ Received 13 January 2006; revised 27 February 2006; accepted 1 March 2006; published 8 April 2006.
}

[1] A weakening of the Atlantic Meridional Overturning Circulation (AMOC) in the next century is simulated by most state-of-the-art coupled models but none of them accounted for land-ice melting. Here we evaluate the impact of this melting on future climate projection using the IPSL-CM4 coupled ocean-atmosphere model. For this purpose we use two different versions of the model, one with a crude land-ice melting parameterization, and the other without. The analysis compares results of experiments where atmospheric $\mathrm{CO}_{2}$ increases by $1 \% / \mathrm{yr}$, performed with the two versions of this model. The AMOC is reduced by $47 \%$ when the melting of land-ice is considered, and represents an extreme melting scenario. This reduction is of $21 \%$ without this melting. It is shown that this difference in AMOC impacts the northern hemisphere mostly through the sea-ice cover feedback. Citation: Swingedouw, D., P. Braconnot, and O. Marti (2006), Sensitivity of the Atlantic Meridional Overturning Circulation to the melting from northern glaciers in climate change experiments, Geophys. Res. Lett., 33, L07711, doi:10.1029/2006GL025765.

\section{Introduction}

[2] Most climate simulations with state of the art climate models produce a weakening of the Atlantic Meridional Overturning Circulation (AMOC) under greenhouse gas warming [Schmittner et al., 2005]. An important spread in the magnitude of this reduction between models has been observed. It has now been established that this weakening is primarily due to the increase in temperature at high latitude [Gregory et al., 2005]. However, there is large uncertainty in the role of the change in the freshwater budget at high latitude. Also the different feedbacks involved with a reduction of AMOC are not well understood, but could be large. Despite the relatively small amount of meridional heat transport driven by the ocean compared to the atmosphere, the AMOC has a very strong impact on the climate because it contributes to modifying the ocean heat budget at high latitude, thus interacting with sea-ice properties. A decrease in the AMOC diminishes the heat transport and may also increase the seaice cover, which is likely to increase the atmospheric cooling of the northern hemisphere through the sea-ice albedo feedback [Schmittner et al., 2002; Winton, 2003].

[3] The aim of this paper is to investigate the role of landice melting in future climate scenarios. Models used for last IPCC [Cubasch et al., 2001] did not take into account the melting of the ice-sheets and glaciers in the hydrological balance of the North Atlantic. This process is however of

\footnotetext{
${ }^{1}$ Institut Pierre Simon Laplace/Laboratoire des Sciences du Climat et de l'Environnement, Gif-sur-Yvette, France.
}

Copyright 2006 by the American Geophysical Union. 0094-8276/06/2006GL025765 importance, because the associated freshening of the convection sites, located in the Labrador and Nordic Seas, could lead to a decrease in AMOC. Therefore this melting needs to be accounted for to better understand and quantify the climatic impact of the AMOC reduction. The last IPCC [Cubasch et al., 2001] estimated that melting of Greenland glaciers would contribute to a sea level rise of about $9 \mathrm{~cm}$ in the next century, which represents about $0.04 \mathrm{~Sv}(1 \mathrm{~Sv}=$ $10^{6} \mathrm{~m}^{3} / \mathrm{s}$ ) or a decrease of $5 \%$ of the Greenland ice sheets. The contribution of the other glaciers and uncertainty on the process of land-ice melting as well as the uncertainty in the warming for the next century [Gregory et al., 2004] could lead to a "worst case" estimates of the order of $0.1 \mathrm{~Sv}$ for the North Atlantic freshening due to land-ice melting [Parizek and Alley, 2004].

[4] Here we investigate the role of melting of the icesheets and glaciers in coupled land-ocean-atmosphere-seaice simulations where the $\mathrm{CO}_{2}$ concentration rises by $1 \%$ per year. We consider two simulations for which the coupled model differs only in the representation of landice. The first one incorporates a crude parametrization of the land-ice melting, whereas in the second one, land-ice melting is not allowed. Similar investigation was presented by Fichefet et al. [2003], with an interactive coupling between the climate model and a comprehensive model of the Greenland ice-sheets. Here we consider a more extreme warming and melting scenario on a longer time scale. Consequently our AMOC response is larger than in the Fichefet et al. study. In addition we do not limit the analysis to the quantification of the change in AMOC, but we also consider how the AMOC interferes with the sea-ice albedo feedback and global warming.

\section{Model Description and Experiments \\ 2.1. IPSL Coupled Model}

[5] The model used in this study is the version 4 of the "Institut Pierre Simon Laplace" (IPSL-CM4) global atmosphere-ocean-sea ice coupled model [Marti et al., 2005]. It couples the atmosphere general circulation model LMDz and the ocean general circulation model ORCA/OPA. A sea-ice model, which computes ice thermodynamics and dynamics, is included in the ocean model and coupled with the atmosphere. The atmospheric model is coupled to the ORCHIDEE land-surface scheme. The ocean and atmosphere exchange surface temperature, sea-ice cover, momentum, heat and freshwater fluxes once a day, using the OASIS coupler. River runoff and ice stream schemes close the water budget between land and ocean. No flux correction is applied and the coupling scheme ensures both global and local conservation of heat and freshwater fluxes at the model interfaces. 


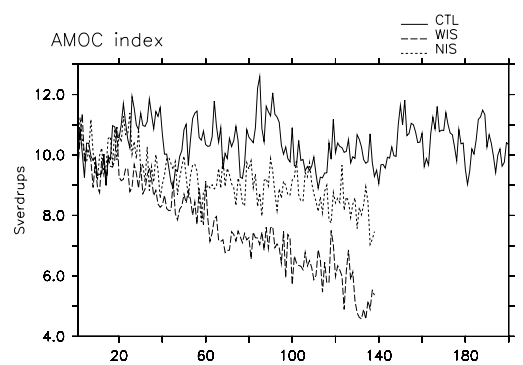

Figure 1. AMOC index for the different simulations. It is defined as the maximum of the Atlantic meridional overturning circulation between $500 \mathrm{~m}$ and $5000 \mathrm{~m}$ depth, expressed in Sverdups $\left(1 S v=10^{6} \mathrm{~m}^{3} \cdot \mathrm{s}^{-1}\right)$. In solid line is the CTL simulation, in dotted line, the WIS experiment, and in dashed line, the NIS experiment.

[6] The model is run with an horizontal resolution of 96 points in longitude and 71 points in latitude $\left(3.7^{\circ} \times 2.5^{\circ}\right)$ for the atmosphere and 182 points in longitude and 149 points in latitude for the ocean, corresponding to a resolution of about $2^{\circ}$, with higher latitudinal resolution of $0.5^{\circ}$ in the equatorial ocean. There are 19 vertical levels in the atmosphere and 31 levels in the ocean with the highest resolution $(10 \mathrm{~m})$ in the upper $150 \mathrm{~m}$.

\subsection{Closure of the Freshwater Budget}

[7] Each atmospheric grid-box could contain up to 4 different subsurfaces in order to represent properly surface fluxes according to the different surface characteristics (land, ocean, sea-ice, land-ice). Over land-ice, surface temperature is computed considering radiative fluxes, latent and sensible heat fluxes, diffusion with the underlying ice surfaces, as well as snow and ice melting. Ice is allowed to melt when there is no more snow on the grid-box. To close the water budget at high latitude, the runoff corresponding to the snow and ice melting is routed to the ocean. The method employed mimics the effect of ice calving and icebergs. The freshwater is therefore not directly distributed along the ice sheet, but uniformly over a wider region. Earth is divided into three latitude bands with limits at $90 \mathrm{~S} / 50 \mathrm{~S} /$ $40 \mathrm{~N} / 90 \mathrm{~N}$. For the northern band, the calving is send to the Atlantic and the Arctic, but not to the Pacific. The parametrization of the land-ice melting is valid as long as the horizontal extent of the ice-sheet does not change with time. This assumption is therefore only valid for short term integration of global warming experiments. Our results suggest that this assumption is violated at the end of the experiments, suggesting that the parameterization needs to be improved in future experiments.

\subsection{Experiments}

[8] We consider transient simulation where atmospheric $\mathrm{CO}_{2}$ concentration starts at the preindustrial concentration of $280 \mathrm{ppm}$, and increases by $1 \% / \mathrm{yr}$ reaching $4 \times \mathrm{CO}_{2}$ $(1120 \mathrm{ppm})$ in 140 years. Two versions of the model are considered. The first one takes into account the whole parametrization for land-ice. The second one does not take into account the melting of land-ice, but keeps all the other terms, notably the land-snow melting. This is designed to isolate the effect of the melting of glaciers when temperature increases. This melting is equal to zero in the control simulation (CTL) with atmospheric $\mathrm{CO}_{2}$ of $280 \mathrm{ppm}$, so that these two different parameterizations lead to the same CTL. The first scenario with ice-sheet melting will be referred to as WIS in the following. The second one with no melting is called NIS. Difference in freshwater forcing between the two experiments above $40^{\circ} \mathrm{N}$ increases nearly linearly (not shown) from 0 up to $0.1 \mathrm{~Sv}$ after 70 years $\left(2 \times \mathrm{CO}_{2}\right)$ and up to $0.2 \mathrm{~Sv}$ at $4 \times \mathrm{CO}_{2}$. These are quite large values and represent a "worst case" melting scenario. The land-ice melting in the other latitude bands is negligible.

\section{Results}

\subsection{Response of the AMOC and Global Temperature Change}

[9] As expected the land-ice melting has a profound impact on the simulated reduction of AMOC. Under modern conditions, AMOC simulated by IPSL-CM4 reaches $10.4 \mathrm{~Sv}$ (Figure 1). This is weaker than the $15 \pm 2 \mathrm{~Sv}$ observation-based estimates of North Atlantic Deep Water production rates [Ganachaud and Wunsch, 2000]. It results from an absence of convection in the Labrador Sea due to an excessive freshening in this region (D. Swingedouw et al., The impact of global freshwater forcing on the thermohaline circulation: Adjustment of North Atlantic Convection Sites in a CGCM, submitted to Climate Dynamics, 2006). However, the reduction of the AMOC under future scenarios is large. In WIS, it decreases by $4.9 \mathrm{~Sv}(47 \%)$ at $4 \times \mathrm{CO}_{2}$ compared to CTL (Figure 1). NIS exhibits a smaller decrease with a reduction of only $2.2 \mathrm{~Sv}(21 \%)$ at $4 \times \mathrm{CO}_{2}$, which is close to the $25 \%$ mean decrease in 2100 in Schmittner et al. [2005] multi-model analysis. Note that the weakness of the AMOC in CTL could lead to a high sensitivity of the AMOC response to the freshwater forcing [Rahmstorf, 1996].

[10] The northward heat transport at $20^{\circ} \mathrm{N}$ in the Atlantic follows this decrease, with a reduction of $0.33 \mathrm{PW}(47 \%)$ in WIS and of $0.15 \mathrm{PW}(21 \%)$ in NIS compared to CTL. Surface air temperature is also affected over the whole northern hemisphere (Figure 2). Compared to NIS, WIS shows a relative cooling, up to more than $5 \mathrm{~K}$ in the regions around the Barents Sea. Two effects could be at the origin of this cooler temperature simulated in WIS than in NIS: a larger reduction of the ocean heat transport linked to the AMOC weakening, or an ocean-sea-ice local response caused by more freshening of the Arctic. We will discrim-

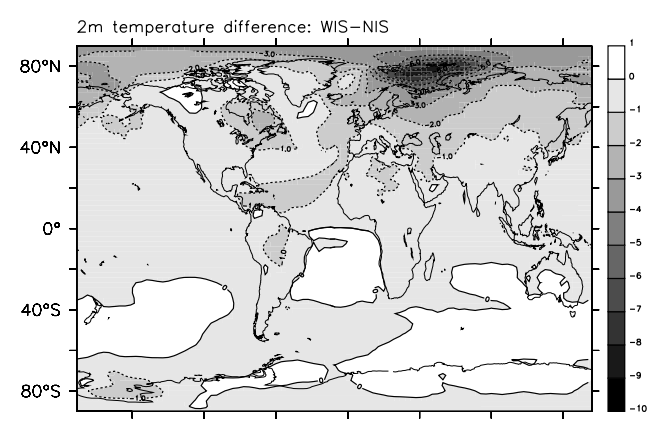

Figure 2. Difference in $2 \mathrm{~m}$ atmospheric temperature between WIS and NIS, averaged over years 121 to 140 . The contour interval is $1 \mathrm{~K}$. 


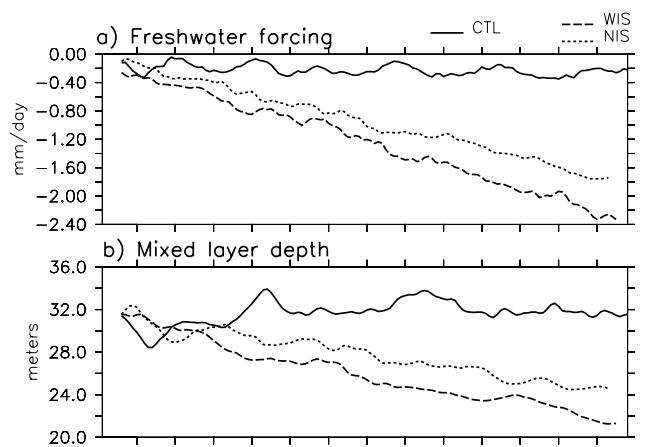

c) SST

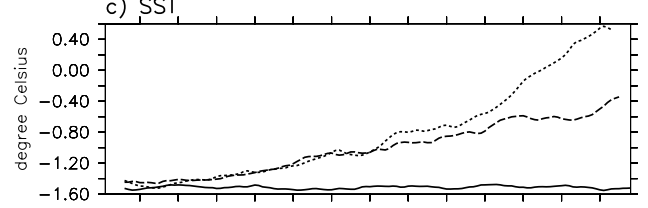

-1.60 d) Ice-cover

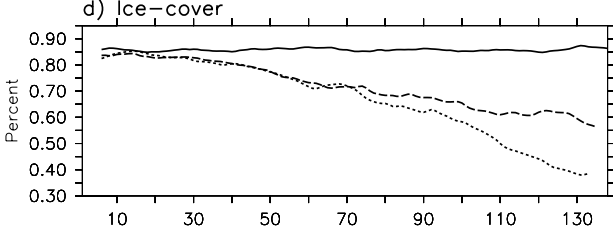

Figure 3. Trend of (a) freshwater forcing in $\mathrm{mm} / \mathrm{day}$, (b) mixed layer depth in meters, (c) Sea Surface Temperature (SST) in ${ }^{\circ} \mathrm{C}$, and (d) Ice-cover in \%, averaged the Arctic basin. The Nordic Seas are excluded. In solid line is the CTL simulation, in dotted line, the WIS experiment, and in dashed line, the NIS experiment.

inate which of these two processes is more effective in the following.

\subsection{Analysis of the Transient Response in the Aretic}

[11] Differences in the freshwater forcing between NIS and WIS appear in the Arctic from the beginning of the transient simulations (Figure 3a). The larger freshening in WIS could affect Sea Surface Temperature (SST) and sea-ice cover in different ways. First, the corresponding lower salinity diminishes the fusion point and favors the growth of sea-ice. Here, the change in freezing point is less than $0.2 \mathrm{~K}$ and does not seem to significantly increase the ice-cover during the first 70 years (Figure 3d). Also, the lower salinity stratifies the surface ocean, which is reflected in the decrease in mixed layer depth as a function of time (Figure 3b). This change in mixed layer depth may reduce the heat capacity of the surface layer, and could affect the SST. However, the difference between the two transient simulations is less than 2 meters, and no significant changes in SST appear before year 70 between the two transient simulations. Therefore, this process is not likely to be at the origin of the divergence between the simulated evolution of SST (Figure 3c). Last, the geostrophic currents are not altered by the freshwater anomaly because this anomaly is distributed uniformly north of $40^{\circ} \mathrm{N}$ in the ocean and thus has no impact on the local steric gradient [Ottera and Drange, 2004]. Consequently, local processes due to the input of freshwater at high latitude do not seem to be at the origin of the SST and sea-ice cover divergence between the two transient scenarios.

[12] After year 70, statistically significant differences appear in SST and ice-cover between WIS and NIS
(Figures $3 \mathrm{c}$ and $3 \mathrm{~d}$ ). They lag by about 10 years significant change in the AMOC (Figure 1). This lag strongly suggests that differences in the heat transport by the ocean, linked to the AMOC, modifies the heat budget of the Arctic and is at the origin of the differences in SST and sea-ice cover. Indeed the decrease of the northward ocean heat transport at $50^{\circ} \mathrm{N}$ in the North Atlantic is $50 \mathrm{TW}$ stronger in WIS than in NIS around year 60. This difference in heat transport is also observed through the section between the Svalbard and New-Zemble at year 70. This is consistent with the fact that most of the reduced warming in WIS happens in the Barents Sea, which is along the pathway of the upper North Atlantic water entering the Arctic. In addition, there is a strong spatial correlation of more than 0.9 between SST change, sea-ice covering and change in atmospheric temperature in this region (Figure 4). It indicates that the stronger heat transport in NIS triggers the fast sea-ice albedo feedback. The warmer SST favors the melting of sea-ice, which in turn diminishes the sea-ice albedo, and leads to a local increase in atmospheric temperature above the Barents Sea. The warming then extends to all latitudes by the way of atmospheric circulation, which explains the large warming found over sea-ice and surrounding continents. In WIS, SST are colder and sea-ice still expands in this region, thus reducing the impact of global warming in northern high latitudes (Figure 2).

\subsection{AMOC Change and Transient Climate Sensitivity}

[13] Section 3.2 shows that the difference in AMOC between the two simulations triggers fast feedbacks at high latitude. Here, we analyse how these feedbacks impact global climate sensitivity at $4 \times \mathrm{CO} 2$, defined as the difference in global surface temperature between the transient simulations and CTL averaged between years 121 to 140 . WIS shows global surface temperature warming of $4.25 \mathrm{~K}$ at $4 \times \mathrm{CO} 2$ compared to CTL. This global warming is $10.4 \%$ higher in NIS. To understand this difference we analyse the differences in key feedbacks between the two simulations, focusing on: 1) sea-ice/albedo feedback, 2) water vapor feedback and 3) cloud feedback.

[14] For each simulation, changes in top-of-atmosphere net clear-sky short-wave radiation relative to CTL are mostly due to changes in ice and snow cover (not shown [Meehl et al., 2003]). This allows us to estimate that the

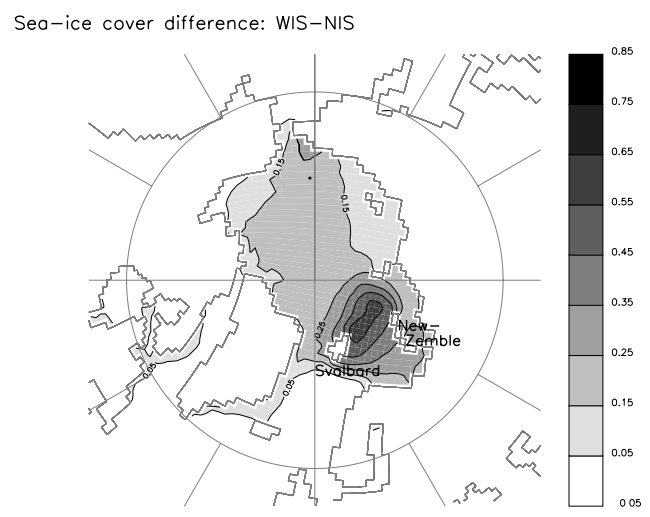

Figure 4. Difference in sea-ice cover (in \%) between WIS and NIS averaged between years 121 to 140 . The contour interval is $0.1 \%$. 
melting of ice and snow represents an increased heat gain for the climate system of $3.09 \mathrm{~W} / \mathrm{m}^{2}$ at the top of the atmosphere in WIS, and of $3.56 \mathrm{~W} / \mathrm{m}^{2}$ in NIS at the time of $4 \times \mathrm{CO} 2$. Thus, the sea-ice albedo feedback is $15.2 \%$ more efficient in NIS, explaining part of the temperature difference at $4 \times \mathrm{CO} 2$ between the two transient simulations. The water vapor also played a role. This feedback is measured as by Ramanathan and Collins [1991] by the difference between change in top-of-atmosphere net clear-sky longwave radiation and the surface change in radiative emission due to surface warming. It provides an indication of the change in the greenhouse effect of the cloud free atmosphere. It goes from $12.74 \mathrm{~W} / \mathrm{m}^{2}$ in WIS to $14.36 \mathrm{~W} / \mathrm{m}^{2}$ in NIS. It is thus $12.4 \%$ higher in NIS. The cloud feedback also exhibits significant change between NIS and WIS: the difference in total cloud radiative forcing with CTL (the sum of cloud shortwave and cloud long-wave radiative forcing) is of $2.05 \mathrm{~W} / \mathrm{m}^{2}$ in WIS and of $2.32 \mathrm{~W} / \mathrm{m}^{2}$ in NIS, corresponding to an additional $12.8 \%$ increase for the latter simulation. The cloud feedback increase results from a reduction of low cloud cover in the northern hemisphere in NIS (not shown) as earlier discussed by Winton [2003].

\section{Conclusions}

[15] In this study, we have quantified the impact of landice melting in future climate scenario simulations, with the IPSL coupled model. Two versions of this model have been considered, one without the land-ice melting, like in all models participating in the last and current IPCC [Cubasch et al., 2001], and the other with a simple parametrization of this melting. Difference in the simulated temperature, as $\mathrm{CO}_{2}$ increases, becomes very large between the two scenarios performed with the two versions of the model. When land-ice is allowed to melt, the global surface temperature is $0.44 \mathrm{~K}(10 \%)$ lower at $4 \times \mathrm{CO}_{2}$, which represents a noticeable uncertainty on climate sensitivity. This is attributed to a $28 \%$ larger reduction of the AMOC in this simulation. A smaller ocean heat transport to the Arctic appears, which in turn maintains the sea-ice cover and thus the albedo. This effect is also reinforced by the water vapor and cloud positive feedbacks. It is important to note that it takes 70 years before the cumulative effect of the additional freshwater is sufficient to modify the AMOC changes, leading to a larger melting of sea-ice in NIS. When this happens, fast ice albedo, water vapor and cloud feedbacks enter into play and contribute to amplifying the difference between NIS and WIS. The northern hemisphere is mostly affected with a $0.85 \mathrm{~K}$ warming, while the southern hemisphere shows a small cooling of $0.07 \mathrm{~K}$. An important warming of greater than $5 \mathrm{~K}$ appears around the Barents Sea, where sea-ice cover is strongly affected. These regions are the starting point of the extension of the larger warming in the Northern hemisphere.

[16] The impact of land-ice melting is thus primordial and must be taken into account in the next generation of coupled models. In the IPSL-CM4 model, the parametrization of this process is very crude. The anomaly in freshwater due to land-ice melting is more than $0.1 \mathrm{~Sv}$ after 100 years, and accounts for a melting of $20 \%$ of the Greenland land-ice at the end of the 140 years of integration. All in all, the results of this analysis stress the fact that the closure of the water cycle needs to be carefully accounted for to improve our understanding of the role of the ocean in the future climate. The land-ice melting is part of the processes that must be considered. Further study with a multi model ensemble may be necessary to better constrain the uncertainty about this process. Our results also confirm the importance of the AMOC on the northern hemisphere climate, mostly through sea-ice interaction.

[17] Acknowledgment. This study benefits from interesting discussion with P. Delecluse and E. Guilyardi. The computing time was provided by the Commissariat a l'Energie Atomique (CEA).

\section{References}

Cubasch, U., et al. (2001), IPCC Third Assessment Report of Climate Change, chap. 8, Cambridge Univ. Press, New York.

Fichefet, T., C. Poncin, H. Goosse, P. Huybrechts, I. Jansses, and H. Le Treut (2003), Implication of changes in freshwater flux from the Greenland ice sheet for the climate of the 21 st century, Geophys. Res. Lett., 30(17), 1911, doi:10.1029/2003GL017826.

Ganachaud, A., and C. Wunsch (2000), Improved estimates of global ocean circulation, heat transport and mixing from hydrographic data, Nature, 407, 453-457.

Gregory, J. M., P. Huybrechts, and S. C. B. Raper (2004), Threatened loss of the Greenland ice-sheet, Nature, 428, 616.

Gregory, J. M., et al. (2005), A model intercomparison of changes in the Atlantic thermohaline circulation in response to increasing atmospheric CO2 concentration, Geophys. Res. Lett., 32, L12703, doi:10.1029/ 2005GL023209.

Marti, O., et al. (2005), The new IPSL climate system model: IPSL-CM4, Note du Pole de Modelisation 26, 88 pp., Inst. Pierre Simon Laplace, Paris.

Meehl, G. A., W. M. Washington, and J. M. Arblaster (2003), Long-term global warming scenarios computed with an efficient coupled climate model, J. Clim., 43, 353-367.

Ottera, O. H., and H. Drange (2004), A possible feedback mechanism involving the Arctic freshwater, the Arctic sea ice, and the north Atlantic drift, Adv. Atmos. Sci., 21, 784-801.

Parizek, B. R., and R. B. Alley (2004), Implications of increased Greenland surface melt under global-warming scenarios: Ice-sheet simulations, Quat. Sci. Rev., 23, 1013-1027.

Rahmstorf, S. (1996), On the freshwater forcing and transport of the Atlantic thermohaline circulation, Clim. Dyn., 12, 799-811.

Ramanathan, V., and W. Collins (1991), Thermodynamic regulation of ocean warming by cirrus clouds deduced from observations of the 1987 El Nino, Nature, 351, 27-32.

Schmittner, A., K. J. Meissner, M. Eby, and A. J. Weaver (2002), Forcing of the deep ocean circulation in simulations of the Last Glacial Maximum, Paleoceanography, 17(2), 1015, doi:10.1029/2001PA000633.

Schmittner, A., M. Latif, and B. Schneider (2005), Model projections of the North Atlantic thermohaline circulation for the 21 st century assessed by observations, Geophys. Res. Lett., 32, L23710, doi:10.1029/ 2005GL024368.

Winton, M. (2003), On the climatic impact of ocean circulation, J. Clim., $16,2875-2889$.

P. Braconnot, O. Marti, and D. Swingedouw, Institut Pierre Simon Laplace/Laboratoire des Sciences du Climat et de l'Environnement, Orme des merisiers, F-91191 Gif-sur-Yvette, France. (didier.swingedouw@cea.fr) 